\title{
Incidence of New-Onset Pain, Characteristics and Influence on Health-Related Quality of life in COVID- 19 Survivors After Critical Illness. Analysis of the PAIN COVID Clinical Trial cohort.
}

\section{Antonio Ojeda}

Clinic Barcelona Hospital Anaesthesiology Reanimation and Pain Therapy: Hospital Clinic de Barcelona Servei d'Anestesiologia Reanimacio i Tractament del Dolor

Andrea Calvo ( $\square$ macalvo@clinic.cat)

Clinic Barcelona Hospital Anaesthesiology Reanimation and Pain Therapy: Hospital Clinic de Barcelona Servei d'Anestesiologia Reanimacio i Tractament del Dolor https://orcid.org/0000-0001-8249-1226

Tomas Cuñat

Clinic Barcelona Hospital Dolor Clinic: Hospital Clinic de Barcelona Servei d'Anestesiologia Reanimacio i Tractament del Dolor

\section{Ricard Mellado Artigas}

Clinic Barcelona Hospital Anaesthesiology Reanimation and Pain Therapy: Hospital Clinic de Barcelona Servei d'Anestesiologia Reanimacio i Tractament del Dolor

\section{Oscar Comino-Trinidad}

Clinic Barcelona Hospital Dolor Clinic: Hospital Clinic de Barcelona Servei d'Anestesiologia Reanimacio i

Tractament del Dolor

\section{Jorge Aliaga}

Clinic Barcelona Hospital Dolor Clinic: Hospital Clinic de Barcelona Servei d'Anestesiologia Reanimacio i Tractament del Dolor

\section{Marilyn Arias}

Clinic Barcelona Hospital Dolor Clinic: Hospital Clinic de Barcelona Servei d'Anestesiologia Reanimacio i Tractament del Dolor

\section{Carlos Ferrando}

Clinic Barcelona Hospital Anaesthesiology Reanimation and Pain Therapy: Hospital Clinic de Barcelona Servei d'Anestesiologia Reanimacio i Tractament del Dolor

\section{Graciela Martínez}

Clinic Barcelona Hospital Anaesthesiology Reanimation and Pain Therapy: Hospital Clinic de Barcelona Servei d'Anestesiologia Reanimacio i Tractament del Dolor

\section{Christian Dürsteler}

Clinic Barcelona Hospital Dolor Clinic: Hospital Clinic de Barcelona Servei d'Anestesiologia Reanimacio i Tractament del Dolor 


\section{Research}

Keywords: COVID-19, Anxiety disorders, Depressive disorders, Quality of life, Post ICU syndrome, chronic pain, critical illness

Posted Date: December 14th, 2020

DOl: https://doi.org/10.21203/rs.3.rs-125421/v1

License: (9) This work is licensed under a Creative Commons Attribution 4.0 International License. Read Full License 


\section{Abstract}

Background: To explore the incidence and characteristics of new-onset pain, its impact on quality of life (HRQoL), and to quantify the presence of mood disorders in critically ill COVID-19 survivors.

Methods: This is a preliminary report of PAIN-COVID clinical trial (NCT04394169) presenting a descriptive analysis in critical ill COVID 19 survivors one month after hospital discharge. Pain was assed using the Brief Pain Inventory short form, Douleur Neuropathique 4 Questions test and Pain Catastrophizing Scale. Health related quality of life (HRQoL) was evaluated with EQoL-5D/5L and mood disorders with Hospital Anxiety and Depression test (HAD).

Results: From May $27^{\text {th }}$ to July $19^{\text {th }} 2020,203$ patients were consecutively screened for eligibility and 65 were finally included in this analysis. In 33 (50.8\%) patients a new-onset pain was reported: 18 (54.5\%) reported clinically significant intense pain, 11 (33.3\%) a positive screening for neuropathic pain, 3 (9.1\%) clinically relevant pain catastrophizing thoughts, 29 (87.9\%) pain in $\geq 2$ body sites and $5(15.2 \%)$ widespread pain. Median EQoL-5D/5L index value and visual analogue scale was 0.8 (IQR 0.57-0.87) and 70 (IQR 60-80) respectively. Pain intensity was negatively correlated both to the former (Spearman Rho: $-0.546, p<0.001$ ) and to the latter (Spearman Rho: $-0.387, p=0.001$ ). A HAD anxiety and depression value over 8 were obtained in $7(10,8 \%)$ and $5(7,7 \%)$ of patients, respectively.

Conclusion: The incidence of new-onset pain in critically ill COVID-19 survivors is high and it was associated with a lower HRQoL.

Trial registration: NCT04394169. Registered 19 May 2020.

https://clinicaltrials.gov/ct2/show/NCT04394169

\section{Introduction}

Long-term problems in physical or mental health status are common in critically ill patients after discharge from ICU. In 2012, a new medical term defined as post intensive care syndrome (PICS) was adopted by the Society of Critical Care Medicine to refer to this entity [1]. Currently, survivors outnumber the deceased by three to one, at one year after ICU admission[2]. However, this success has come at the cost of increasing disability and decreasing survivors' quality of life (QoL), which also impacts negatively on caregivers[3][4][5][6]. Critical illness survivors display a high prevalence of moderate to extreme chronic pain, with the latter entailing a significant limitation in work and social activity and becoming a major cause of disability in Europe [7][8].

COVID-19 has led to a large number of hospital admissions. Until November 28th, more than sixty-one million cases of COVID-19 have been reported worldwide [9] with up to 5 percent patients requiring further admission to the ICU [10][11]. Despite this large number of individuals potentially affected by PICS, to 
date, studies reporting data on critically ill COVID-19 patients' pain and self-perceived quality of life have been inexistent. Given that the early treatment of pain could improve the medium- or long-term outcomes, it is imperative to call for the proper identification and management of this condition.

We hypothesized that survivors of critical illness caused by COVID-19 would often present with pain and display a decrease in self-perceived QoL, as well as an increased incidence of anxiety and depression disorders [12]. We aimed to investigate the prevalence and characteristics of new-onset pain in COVID-19 ICU survivors one month after hospital discharge. Additionally, we aimed to assess the relationship between new onset pain and the pain intensity with the HRQoL, and to quantify the presence of mood disorders.

\section{Methods}

\section{Study design}

This is a preliminary descriptive report of an ongoing single-center clinical trial aimed at evaluating the efficacy of a combined intervention program to mitigate chronic pain in COVID-19 ICU survivors (NCT04394169). The study was approved by the Ethical Committee of the Hospital Clinic of Barcelona (approval number HCB/2020/0549) May 14th, 2020. Participants were enrolled one month after hospital discharge after written informed consent. All study procedures were performed following the ethical standards of the Declaration of Helsinki. This study followed the "Strengthening the Reporting of Observational Studies in Epidemiology (STROBE)" statement guidelines for observational cohort studies[13].

Study population and data collection Critical ill survivors' patients with a confirmed COVID-19 infection from a respiratory tract sample using polymerase chain reaction (PCR) based tests with at least one of the following inclusion criteria were eligible for participation: 1) an Acute Physiology and Chronic Health Evaluation (APACHE) II score at ICU admission over 14 points; 2) ICU length of stay over 10 days; 3) ICUAW (Supplement, Definition D1); 4) delirium during ICU admission (Supplement, Definition D2). We use these criteria according to the criteria recommended by the critical illness monitoring and rehabilitation program by Busico $\mathrm{M}$ et al.[14] The exclusion criteria were the following: 1) [15]; central nervous system degenerative disease (Supplement, Definition D3); 2) terminal illness (Supplement, Definition D4); 3) insufficient understanding of the Spanish language; 4) difficulty in completing follow-up due to a living distance over $50 \mathrm{~km}$ from the Hospital Clínic of Barcelona); 5) not providing informed consent for the study.

Using the clinical database of our center, we identified all the patients discharged from the intensive care units and we selected those that met selection criteria. Once the patients were discharge from the hospital, one month after, were contacted telephonically to check for participation and were invited to an introductory interview where they were informed about the study. After enrolment, a baseline interview was conducted. Demographic data and socioeconomic data along with medical history, including mental 
health and chronic pain disorders were collected. Information regarding the recent ICU stay also was included. Finally, patients were interviewed to assess pain, QoL and mood disorders (Supplement 2, Questionnaires) by researchers (AC, TC, OC, JA, MA)

\section{Study definitions and outcomes}

New-onset pain and its characteristics

New-onset pain was evaluated by the BPI-SF questionnaire (Supplement, Questionnaire Q1). Pain location, intensity and interference were registered using the specific questions of BPI-SF. Following the Initiative on Methods, Measurements, and Pain Assessment in Clinical Trials (IMMPACT) recommendations, clinically significant pain was defined as mean BPI-SF intensity score greater than or equal to 3[16]. The definition of new onset pain was an affirmative answer to the first question of BPI-SF questionnaire: "Throughout our lives, most of us have had pain from time to time (such as minor headaches, sprains, and toothaches). Have you had pain other than these everyday kinds of pain?". Widespread pain was also assessed (Supplement, Definition D5). When a new onset pain was detected, neuropathic pain and pain catastrophizing were screening with the DN4 (Supplement, Questionnaire Q2) and assessed with the PCS (Supplement, Questionnaire Q4), respectively.

\section{HRQoL}

HRQoL assessed with the EQoL-5D/5L (Supplement, Questionnaire Q2)[17] determines QoL according to a descriptive system, a VAS and an index value. The descriptive system evaluates five dimensions: mobility, self-care, usual activities, pain/discomfort, and anxiety/depression, each scored according to a scale of 1 (no problems) to 5 (indicating extreme problems). Responses are coded as single-digit numbers expressing the severity level selected at each dimension. The digits for the five dimensions can be combined in a 5-digit code that describes the respondent's health state. The VAS measure of the patient's perception of their overall current health, from 0 -the worst imaginable health- to 100 -the best imaginable health. An index value can also be obtained by applying a formula that attaches values (weights) to each of the levels in each dimension. The index is calculated by deducting the appropriate weights from 1, the value for full health (i.e. state 11111) [18]. The index was obtained by using the EQoL5D/5L Index Value Calculator (Developed by the EuroQol Group Version 2.0.) [19].

\section{Relationship between new-onset pain and health-related quality of life}

The EQoL-5D/5L VAS and index values between individuals presenting with pain and those without it were compared. The relationship between pain intensity and HRQoL was also assessed.

\section{Anxiety and depression}

The presence of anxiety and/or depression was assessed by the HAD (Supplement, Questionnaire Q5).

\section{Statistical analysis}


No sample size calculation was carried out for this preliminary analysis. Importantly, during the analysis of this descriptive project, no outcomes for the ongoing clinical trial have been assessed. Continuous variables were expressed as median (interquartile range), and categorical variables were presented as numbers (percentages). Missing data was minimal (below 0.5\%) and missing observations were not imputed. Comparisons between groups were conducted with Mann-Whitney test. Correlations between ordinal variables were analyzed with Spearman's Rho without accounting for interactions of any order. We used a threshold of 0.05 for statistical significance. All reported tests are two-sided. The $\mathrm{R}$ software was used for all the analysis (R Foundation for Statistical Computing, Vienna, Austria).

\section{Results}

From May 27th to July 19th 2020, 203 critically ill COVID-19 ICU survivors were consecutively screened and 65 patients were finally included in the study and completed the questionnaires. Patients' flowchart is shown in Fig. 1. Patients' characteristics and demographic data are presented in Table 1. 
Table 1

Demographic data.

\begin{tabular}{|c|c|}
\hline Characteristics & \\
\hline Age (years) & 65.0 (57.0 to 70.0$)$ \\
\hline Sex & Female: 17 (26,2 ); Male: $48(73,8)$ \\
\hline Smoke History & $25(38,5)$ \\
\hline Body Mass Index (kg/m2) & 27 (25.0 to 31.4$)$ \\
\hline History of psiquiatric disease & $10(15,4)$ \\
\hline History of chronic pain & $8(12.3)$ \\
\hline Type of Chronic Pain & Focal $7(87,5)$; Widespread $1(12,5)$ \\
\hline Opioid Tolerance Patient & $4(6.2)$ \\
\hline Barthel Index & 100.0 (95.0 to 100.0$)$ \\
\hline Charlson Index score & $3.0(2.0$ to 4.0$)$ \\
\hline S.O.F.A & 5.0 (3.0 to 7.0$)$ \\
\hline A. P.A.C.H.E II & $12.0(9.0$ to 15.0$)$ \\
\hline Mechanical ventilation & $50(76.9)$ \\
\hline Mechanical ventilation (days) & 15.0 (9.0 to 22.0$)$ \\
\hline Tracheostomy & $34(52.3)$ \\
\hline Use of neuromuscular blocking agents & $31(47.7)$ \\
\hline Just No Invasive Ventilation (high flow 02) & $20(30.8)$ \\
\hline Hypoxemia > 24h & $60(92,3)$ \\
\hline Sepsis & $42(64,6)$ \\
\hline Vassopresor Therapy & $49(75.4)$ \\
\hline Total Corticoids Dose (mg) & 1968.0 (1267.0 to 2700.0$)$ \\
\hline Sedation (total days) & 15.0 (9.0 to 20.0$)$ \\
\hline Acute Renal Injury & $28(43.1)$ \\
\hline Replacement renal Therapy & $5(7.7)$ \\
\hline D-Dimerum Maximun (ng/ml) & 6400.0 (3400.0 to 10000.0$)$ \\
\hline Ferrityn Maximun (ng/ml) & 1968.0 (1267.0 to 2700.0$)$ \\
\hline C-reactive protein Maximun (mg/dL) & 20.3 (12 to 27 ) \\
\hline
\end{tabular}




\begin{tabular}{|lc|}
\hline Days with incresed C-reactive protein & $8(5$ to 18$)$ \\
\hline LOS $_{\text {ICU }}$ & $25.0(15.0$ to 33.0$)$ \\
\hline LOS $_{\text {Hospital }}$ & $36.0(25.0$ to 47.0$)$ \\
\hline
\end{tabular}

New-onset Pain and Characteristics.

$33(50.8 \%)$ patients presented new-onset pain, of whom 18 (54.5\%) reported it to be clinically significant in intensity (BPI-SF intensity score $\geq 3$ ), 11 (33.3\%) patients reported neuropathic pain and $3(9.1 \%)$ patients clinically relevant level of catastrophizing. Median BPI-SF score was 3 (IQR 2-4) for intensity and 3 (IQR 1-5) for interference. Figure 2 shows the BPI intensity score and its self-perceived impact on daily life activities. Among those experiencing pain, 29 (87.9\%) patients reported pain in two or more body sites and $5(15.2 \%)$ reported widespread pain. Upper extremities were the most common affected site (18 patients, $54.5 \%)$, followed by lower extremities (12 patients, 34.4\%). 10 (30.3\%) patients reported shoulder pain. Figure 3 shows a body map with the percentage of pain reported in each anatomical area.

\section{HRQOL}

Table 2 shows EQoL-5D/5L frequencies and proportions reported for each dimension and level. Only 9 (5.8\%) patients reported self-perceived full health status. Median EQoL-5D/5L Index Value was 0.8 (IQR 0.57-0.87), and median EQ visual analogic scale (VAS) was 70 (IQR 60-80). 
Table 2

.EQ-5D-5L frequencies and proportions reported by dimension and level at one month after hospital discharge in the evaluated patients

\begin{tabular}{|c|c|c|c|c|c|}
\hline & $\begin{array}{l}\text { Mobility } \\
\text { n (\%) }\end{array}$ & $\begin{array}{l}\text { Self- } \\
\text { Care } \\
n(\%)\end{array}$ & $\begin{array}{l}\text { Usual } \\
\text { Activities } \\
\text { n (\%) }\end{array}$ & $\begin{array}{l}\text { Pain / } \\
\text { Discomfort } n \\
\text { (\%) }\end{array}$ & $\begin{array}{l}\text { Anxiety / } \\
\text { Depression n } \\
\text { (\%) }\end{array}$ \\
\hline $\begin{array}{l}\text { Level } 1 \\
\text { (No problems) }\end{array}$ & $\begin{array}{l}20 \\
(30.8)\end{array}$ & $\begin{array}{l}44 \\
(67.7)\end{array}$ & $35(53.8)$ & $26(40 \%)$ & $38(58.5)$ \\
\hline $\begin{array}{l}\text { Level } 2 \\
\text { (Slight problems) }\end{array}$ & $\begin{array}{l}19 \\
(29.2)\end{array}$ & $\begin{array}{l}10 \\
(15.4)\end{array}$ & $17(26.2)$ & $20(30.8)$ & $20(30.8)$ \\
\hline $\begin{array}{l}\text { Level } 3 \\
\text { (Moderate problems) }\end{array}$ & $21(32.3)$ & $\begin{array}{l}10 \\
(15.4)\end{array}$ & $9(13.8)$ & $16(24.6)$ & $6(9.2)$ \\
\hline $\begin{array}{l}\text { Level } 4 \\
\text { (Severe problems) }\end{array}$ & $4(6.2)$ & $1(1.5)$ & $4(6.2)$ & $3(4.6)$ & - \\
\hline $\begin{array}{l}\text { Level } 5 \\
\text { (Extreme problems/ unable } \\
\text { to do) }\end{array}$ & $1(1.5)$ & - & - & - & $1(1.5)$ \\
\hline
\end{tabular}

\section{New-onset pain and HRQoL}

As expected, individuals displaying new-onset pain had a significant worse EQoL-5D/5L VAS [65 (50-75) vs $80(69-86), p<0.001)]$. In addition, these individuals showed a worse EQoL-5D/5L index value [0.65 $(0.55-0.80)$ vs $0.87(0.80-1), p<0.001)]$. Pain intensity was negatively correlated to EQoL-5D/5L VAS measurements (Spearman Rho: $-0.387, p=0.001$ ) and EQoL-5D/5L index value (Spearman Rho: $-0.546, p$ $<0.001)$, as shown in Fig. 4.

Anxiety and depression disorders.

In $7(10,8 \%)$ patients a HAD anxiety value $\geq 8$ was reported, and $5(7,7 \%)$ patients displayed HAD depression value $\geq 8$.

\section{Discussion}

To our understanding, this is the first study that assesses the incidence of new-onset pain and its influence on the quality of life in critical illness survivor in one specific disease.

We found that half of the critical illness covid-19 survivors report new pain in the first month after hospital discharge, it was frequently associated to a significant worse quality of life. 
The few studies that evaluate new-onset pain in intensive care survivors have been carried out in mixed surgical and medical ICUs, reporting an incidence between $18 \%$ and $44 \%$, depending on the study population, the tool used to assess pain and the time of measurement. (Battle et al, 21; Baumbach et al, NEW BIBLIOGRAPHY (PMID: 26958751; Kroster-Brauwer et al, 22). Although we did our evaluation in a shorter period of time than the studies discussed above, we believe it is important to report these findings to the medical community, so actions can be taken to improve outcomes for these patients.

\section{Characteristics of pain}

Interestingly, one third of the patients suffering from new onset pain had a positive screening for neuropathic pain. Human coronavirus are neurotropic and potentially neurovirulent viruses[20]. It is widely known the association of acute and chronic neuroinflammation with various neurological process[21]. COVID-19 is capable of triggering a cytokine storm in specific populations, with immediate, but also probably lasting effects, on the central and peripheral nervous system[20]. Although there are no conclusive data about the possible persistence of neuroinflammation in survivors of COVID-19 disease, neuropathic pain could be a manifestation of this process that needs to be further investigated.

As it has been observed in previous studies in critical illness survivors, the majority of patients reported pain in multiple body areas, being bilateral symptoms common. Similarly, shoulder pain is also frequently reported[22]. The shoulder joint is vulnerable due to multiple factors such as the relationship of muscle atrophy resulting after relaxation, corticosteroid therapy, sedation and mechanical ventilation [23][20][28]. Other possible causes are invasive devices such as central venous line or dialysis catheter placed in this area[22] or different maneuvers used to move the patients which often depend on the pressure exerted on this joint.[21]. Brachial plexus injury during prone positioning mechanical ventilation has been identified as another potential cause during the pandemic.[24] Therefore, a call has been made for a protocolization of safe proning procedures and an active identification of pain and functional limitation after extubation of the patient[25]. Our results also highlights that $15.2 \%$ of the patients with pain presented widespread pain. A chronic post severe acute respiratory syndrome has been described, as a fibromyalgia-like syndrome[26], in which neuroinflammation would explain this symptomatology. To establish this fact, it would be necessary to demonstrate generalized hyperalgesia (suggesting central sensitization) by means of a quantitative sensory test that should be performed in subsequent studies[27].

Anxiety and depression

We found a lower prevalence of anxiety and depression in this population (HAD anxiety 10.8\%, HAD depression $7.7 \%$ ) than in previously reported non-COVID-19 critically ill patients where it has been documented as high as $46 \%$ and $40 \%$ for anxiety and depression, respectively at 3 months.[28]

Davydow et al. [29] also observed that the median point prevalence of clinically significant depressive symptoms among ICU survivors was 28\% (range 8-57\%) 2 months after hospital discharge. In this systematic review, described a potential for selection bias, due to the voluntary participation. The authors speculated that patients with more severe PICS may refuse to participate in the study due to mood 
disturbances. However, the median point prevalence of clinically significant depressive symptoms described by Davydow et al [29] was $28 \%$, higher than what we found.

Alternatively, the patients could develop a posttraumatic growth, defined as positive changes that a person can experience as a result of struggling with trauma [30]. The so called Polyanna Syndrome, described as being "blind optimistic" to a bad situation[31], could also explain the unexpected low incidence of depression given the survival of to the pandemic.

HRQoL

Up to $69 \%$ of patients displayed some kind of difficulty for mobility in the EQoL-5D/5L questionnaire, whereas the least affected dimension was self-care in $30.8 \%$ of patients Even if many patients were affected in one or more dimension of EQoL-5D/5L, the EQoL-5D/5L VAS evidenced that they had a better perception of their health status than expected, which could be related to the feeling of being a survivor of the pandemic but when the EQoL-5D/5L dimensions are analyzed, the alterations are objectified.

\section{Correlation and clinically significant pain}

The intensity of pain measured with BPI-SF was negatively correlated to both EQoL-5D/5L VAS and EQoL$5 \mathrm{D} / 5 \mathrm{~L}$ index value. This correlation has been described for many pathologies and usually related to an injury as a trigger of pain[32]. The EQoL-5D/5L index value and therefore, the reported HRQoL, was lower in those patients who reported a greater intensity of pain. As far as we know, this is the first study showing the association of clinically significant pain and HRQoL on any type of PICS patients, either COVID-19 or non-COVIID-19 patients. Whether our findings will remain stable over time is not known at this point. However, this research sheds light on the importance of better characterizing physical and mental trajectories after ICU admission to offer best long-term patient care.

\section{Limitations}

This observational study has some limitations. The PAIN-COVID trial excludes patients with neurodegenerative diseases who, presumably. are more prone to suffer chronic pain[33], hence, the incidence of pain after severe COVID-19 disease could have been underestimated. In addition, this preliminary analysis of the PAIN-COVID cohort trial is purely descriptive and the sample size was not aimed for the results presents here. This means that some of the results could be unpowered.

\section{Conclusions}

In this prospective, observational preliminary study we found a high prevalence of new-onset pain in critically ill COVID-19 survivors one month after hospital discharge. Pain was associated with daily life activity limitation and with a lower HRQoL. Future studies are necessary to determine the best treatment strategies for this healthcare problem.

\section{Abbreviations}


ARDS

Acute Respiratory Distress Syndrome

BPI-SF

Brief Pain Inventory-Short Form

COVID-19

Coronavirus disease 2019.

DN4

Douleur Neuropathique en 4 Questions test

EQoL-5D/5L

European Quality of Life-Five Dimensions/Five Levels

HAD

Hospital Anxiety and Depression Test

HRQoL

Health-Related Quality of Life

ICU

Intensive Care Unit

ICU-AW

Intensive Care Unit-Acquired Weakness

MMSE

Mini-Mental State Exam

PCS

Pain Catastrophizing Scale

PICS

Post-Intensive Care Syndrome

QoL

Quality of Life

VAS

Visual Analogue Scale

\section{Declarations}

\section{Ethics approval}

This study was performed in accordance with the tenets of the Helsinki Declaration and has been approved by the authors' institutional review board. This study was approved by the Comité Ético de Investigación Clínica del Hospital Clinic de Barcelona, approval number: HCB/2020/0549, Chairperson: Prof. Joaquin Fores Viñeta, on May 14, 2020.

\section{Consent to participate}

Informed consent has been obtained from all individuals included in this study. 


\section{Consent to publish}

Not applicable.

Availability of data and material: the data that support the findings of this study will be available on www.clinicaltrials.gov or by request to the corresponding author (Dr. Calvo), upon reasonable request.

Code availability: not applicable.

Conflict of interest/Competing interests: The authors declare that they have no competing interests.

\section{Funding:}

The authors received no financial support for the research, the payment for copyright and use of all questionnaire was paid with own resources.

\section{Authors' contributions}

All authors contributed to the study conception and design. The design was performed by Dr. Ojeda. Preparation, patient recruitment and data collection were performed by Dr. Calvo, Dr. Cuñat, Dr. CominoTrinidad, Dr. Aliaga and Dr. Arias. The first draft of the manuscript was written by Dr. Ojeda and Dr. Calvo who share the first authorship of this manuscript with all the authors commented on previous versions of the manuscript. Dr. Mellado Artigas performed data analysis. Dr. Dürsteler , Dra Martinez and Dr. Ferrando have reviewed the different contributions of all the authors and collaborated with the structure of this manuscript. All authors read and approved the final manuscript.

\section{References}

1. Elliott D, Davidson JE, Harvey MA, et al. Exploring the Scope of Post-Intensive Care Syndrome Therapy and Care: Engagement of Non-Critical Care Providers and Survivors in a Second Stakeholders Meeting. Crit Care Med. 2014;42:2518-26. https://doi.org/10.1097/CCM.0000000000000525.

2. Brinkman S, de Jonge $E$, Abu-Hanna A, et al. Mortality After Hospital Discharge in ICU Patients*. Crit Care Med. 2013;41:1229-36. https://doi.org/10.1097/CCM.0b013e31827ca4e1.

3. Torres J, Carvalho D, Molinos E, et al. The impact of the patient post-intensive care syndrome components upon caregiver burden. Med Intensiva. 2017;41:454-60. https://doi.org/10.1016/j.medin.2016.12.005.

4. Herridge MS, Cheung AM, Tansey CM, et al. One-Year Outcomes in Survivors of the Acute Respiratory Distress Syndrome. N Engl J Med. 2003;348:683-93. https://doi.org/10.1056/NEJMoa022450.

5. Herridge MS, Chu LM, Matte A, et al. The RECOVER Program: Disability Risk Groups and 1-Year Outcome after 7 or More Days of Mechanical Ventilation. Am J Respir Crit Care Med. 2016;194:83144. https://doi.org/10.1164/rccm.201512-23430C. 
6. Cameron JI, Chu LM, Matte A, et al. One-Year Outcomes in Caregivers of Critically III Patients. N Engl J Med. 2016;374:1831-41. https://doi.org/10.1056/NEJMoa1511160.

7. Mäkinen OJ, Bäcklund ME, Liisanantti J, et al. Persistent pain in intensive care survivors: a systematic review. Br J Anaesth. 2020;125:149-58. https://doi.org/10.1016/j.bja.2020.04.084.

8. Barbaglia G, Adroher ND, Vilagut G, et al. Health conditions and role limitation in three European Regions: a public-health perspective. Gac Sanit. 2017;31:2-10. https://doi.org/10.1016/j.gaceta.2016.07.008.

9. WHO Coronavirus Disease (COVID-19) Dashboard. https://covid19.who.int. Accessed 17 Sep 2020.

10. Hozhabri H, Piceci Sparascio F, Sohrabi H, et al. The Global Emergency of Novel Coronavirus (SARSCoV-2): An Update of the Current Status and Forecasting. Int $\mathrm{J}$ Environ Res Public Health. 2020;17:5648. https://doi.org/10.3390/ijerph17165648.

11. Ferrando C, Mellado-Artigas R, Gea A, et al (2020) Características, evolución clínica y factores asociados a la mortalidad en UCI de los pacientes críticos infectados por SARS-CoV-2 en España: estudio prospectivo, de cohorte y multi-céntrico. Rev Esp Anestesiol Reanim S0034935620301870. https://doi.org/10.1016/j.redar.2020.07.003.

12. Inoue S, Hatakeyama J, Kondo Y, et al. Post-intensive care syndrome: its pathophysiology, prevention, and future directions. Acute Med Surg. 2019;6:233-46. https://doi.org/10.1002/ams2.415.

13. von Elm E, Altman DG, Egger M, et al. Strengthening the reporting of observational studies in epidemiology (STROBE) statement: guidelines for reporting observational studies. BMJ. 2007;335:806-8. https://doi.org/10.1136/bmj.39335.541782.AD.

14. Busico $M$, das Neves $A$, Carini F, et al. Programa de seguimiento al alta de la unidad de cuidados intensivos. Med Intensiva. 2019;43:243-54. https://doi.org/10.1016/j.medin.2018.12.005.

15. Global Surveillance for human infection with coronavirus disease (COVID-19). https://www.who.int/publications/i/item/global-surveillance-for-human-infection-with-novelcoronavirus-(2019-ncov). Accessed 27 Jul 2020.

16. Gewandter JS, Dworkin RH, Turk DC, et al. Research design considerations for chronic pain prevention clinical trials: IMMPACT recommendations. Pain. 2015;156:1184-97.

17. Badia X, Roset M, Montserrat S, et al. [The Spanish version of EuroQol: a description and its applications. European Quality of Life scale] Med Clin (Barc). 1999;112(Suppl 1):79-85.

18. EQ-5D User Guides - EQ-5D. https://euroqol.org/publications/user-guides/. Accessed 18 Sep 2020.

19. van Hout B, Janssen MF, Feng Y-S, et al. Interim Scoring for the EQ-5D-5L: Mapping the EQ-5D-5L to EQ-5D-3L Value Sets. Value Health. 2012;15:708-15. https://doi.org/10.1016/j.jval.2012.02.008.

20. Wu Y, Xu X, Chen Z, et al. Nervous system involvement after infection with COVID-19 and other coronaviruses. Brain Behav Immun. 2020;87:18-22. https://doi.org/10.1016/j.bbi.2020.03.031.

21. Yachou Y, El Idrissi A, Belapasov V, Ait Benali S. Neuroinvasion, neurotropic, and neuroinflammatory events of SARS-CoV-2: understanding the neurological manifestations in COVID-19 patients. Neurol Sci. 2020;41:2657-69. https://doi.org/10.1007/s10072-020-04575-3. 
22. Battle CE, Lovett $\mathrm{S}$, Hutchings $\mathrm{H}$. Chronic pain in survivors of critical illness: a retrospective analysis of incidence and risk factors. Crit Care. 2013;17:R101. https://doi.org/10.1186/cc12746.

23. Koster-Brouwer ME, Rijsdijk M, van Os WKM, et al. Occurrence and Risk Factors of Chronic Pain After Critical Illness. Crit Care Med. 2020;48:680-7. https://doi.org/10.1097/CCM.0000000000004259.

24. Prone. position in ARDS patients: why, when, how and for whom. https://www.ncbi.nlm.nih.gov/pmc/articles/PMC7652705/. Accessed 11 Nov 2020.

25. BOA A commentary on Prone Position Plexopathy during the COVID-19 pandemic. https://www.boa.ac.uk/policy-engagement/journal-of-trauma-orthopaedics/journal-of-traumaorthopaedics-and-coronavirus/a-commentary-on-prone-position-plexopathy.html. Accessed 21 Sep 2020.

26. Moldofsky H, Patcai J. Chronic widespread musculoskeletal pain, fatigue, depression and disordered sleep in chronic post-SARS syndrome; a case-controlled study. BMC Neurol. 2011;11:37. https://doi.org/10.1186/1471-2377-11-37.

27. Kemp HI, Corner E, Colvin LA. Chronic pain after COVID-19: implications for rehabilitation. $\mathrm{Br} \mathrm{J}$ Anaesth. 2020;125:436-40. https://doi.org/10.1016/j.bja.2020.05.021.

28. Hatch R, Young D, Barber V, et al (2018) Anxiety, Depression and Post Traumatic Stress Disorder after critical illness: a UK-wide prospective cohort study. Crit Care 22:. https://doi.org/10.1186/s13054018-2223-6.

29. Davydow DS, Gifford JM, Desai SV, et al. Depression in general intensive care unit survivors: a systematic review. Intensive Care Med. 2009;35:796-809. https://doi.org/10.1007/s00134-009-13965.

30. Tedeschi RG, Calhoun LG. The Posttraumatic Growth Inventory: measuring the positive legacy of trauma. J Trauma Stress. 1996;9:455-71. https://doi.org/10.1007/BF02103658.

31. Sirgy MJ. (2002) The Psychology of Quality of Life. Springer Netherlands.

32. Langerud AK, Rustøen T, Småstuen MC, et al (2018) Health-related quality of life in intensive care survivors: Associations with social support, comorbidity, and pain interference. PLoS ONE 13:. https://doi.org/10.1371/journal.pone.0199656.

33. Carniglia L, Ramírez D, Durand D, et al (2017) Neuropeptides and Microglial Activation in Inflammation, Pain, and Neurodegenerative Diseases. Mediators Inflamm 2017:. https://doi.org/10.1155/2017/5048616.

\section{Figures}




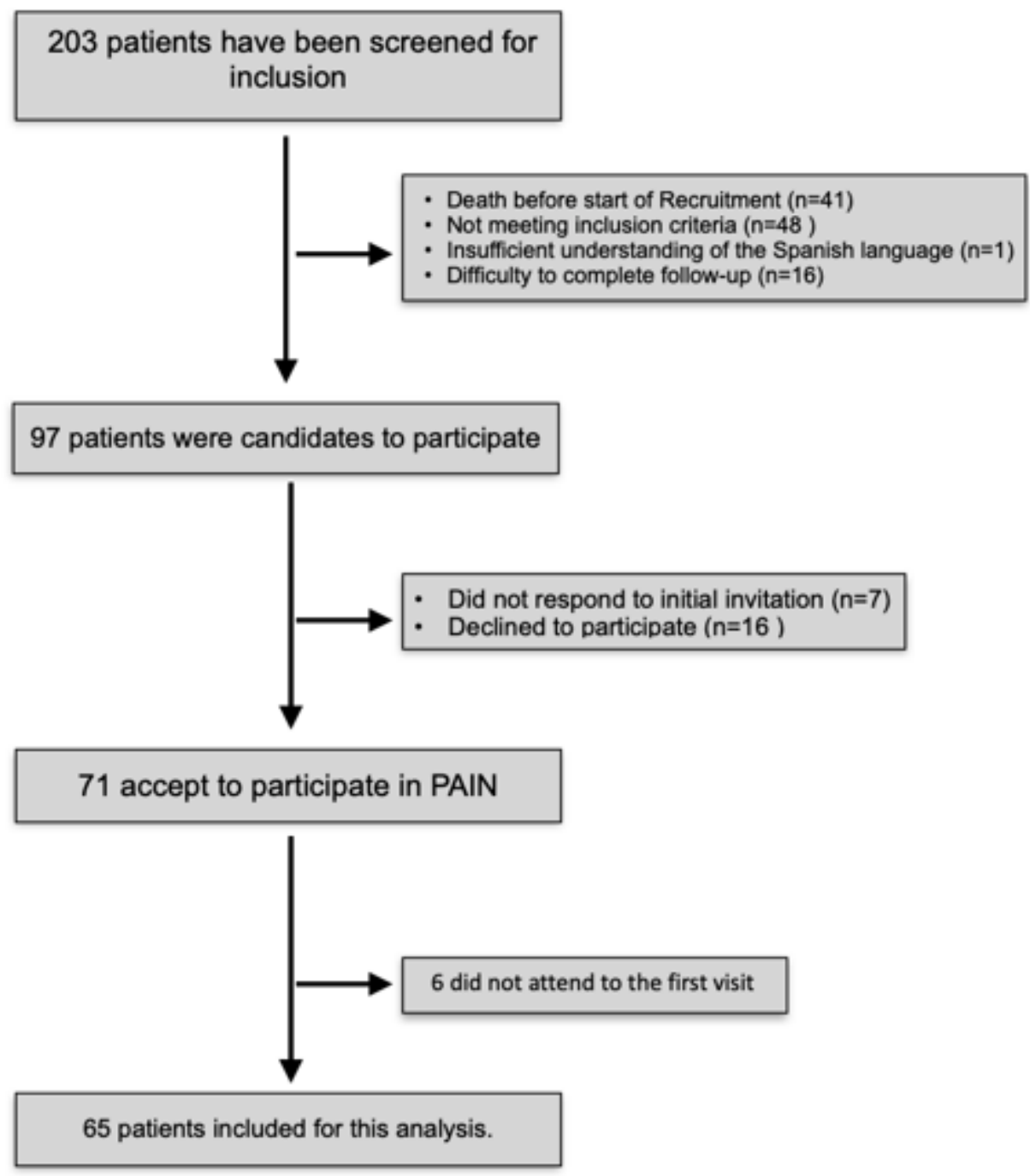

\section{Figure 1}

Study Flowchart. 


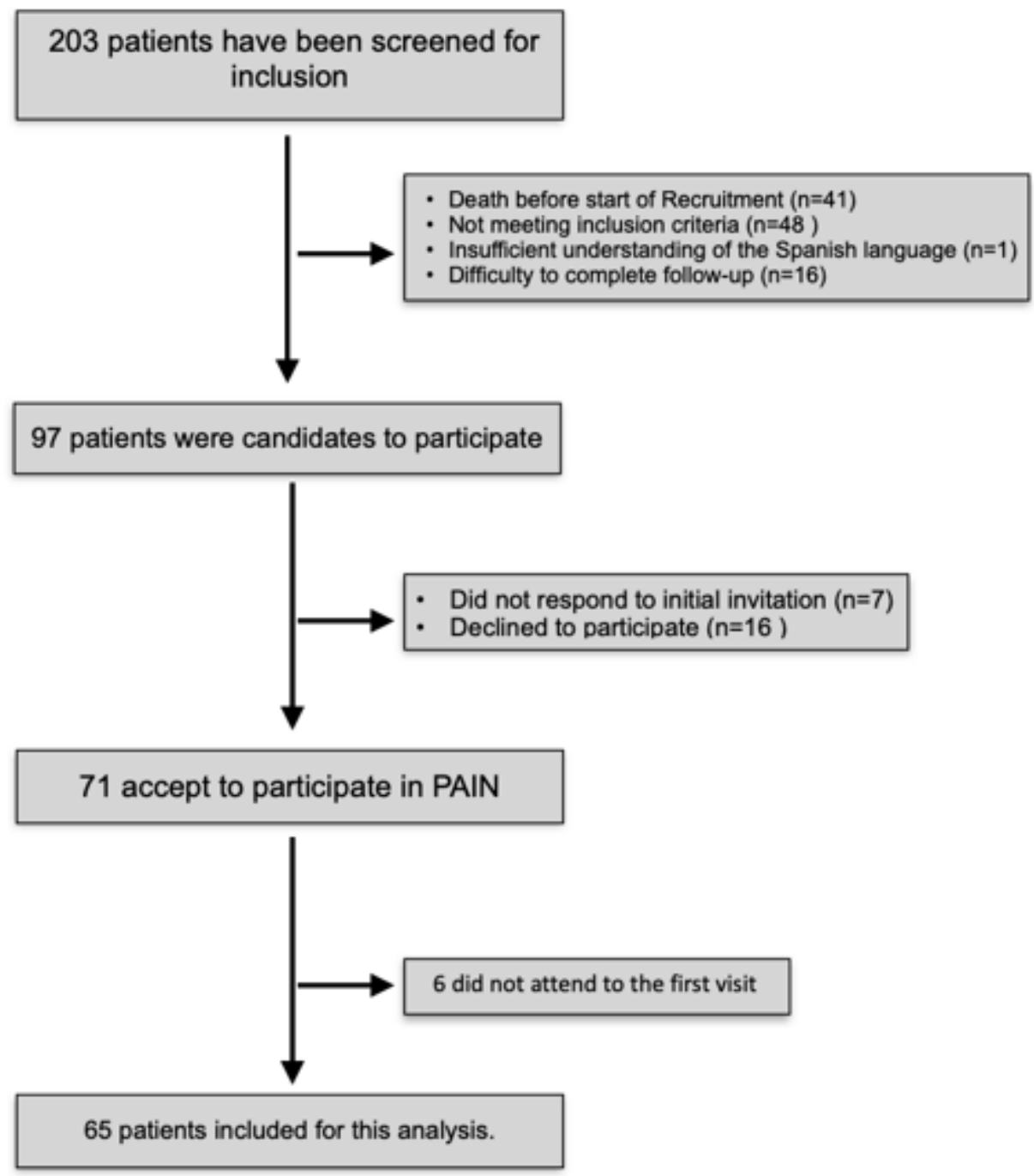

\section{Figure 1}

Study Flowchart.

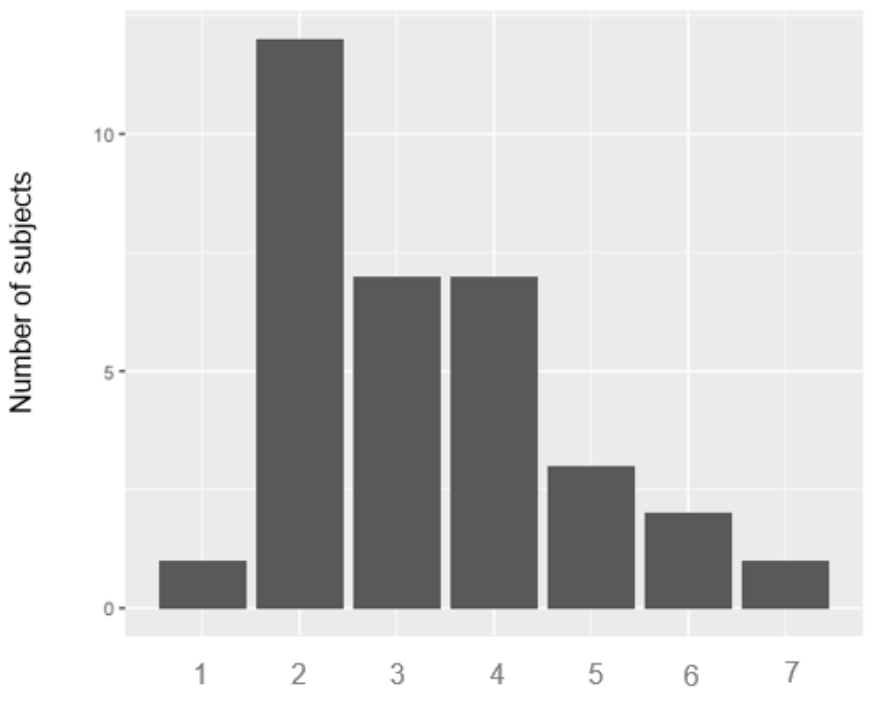

BPI Mean intensity score

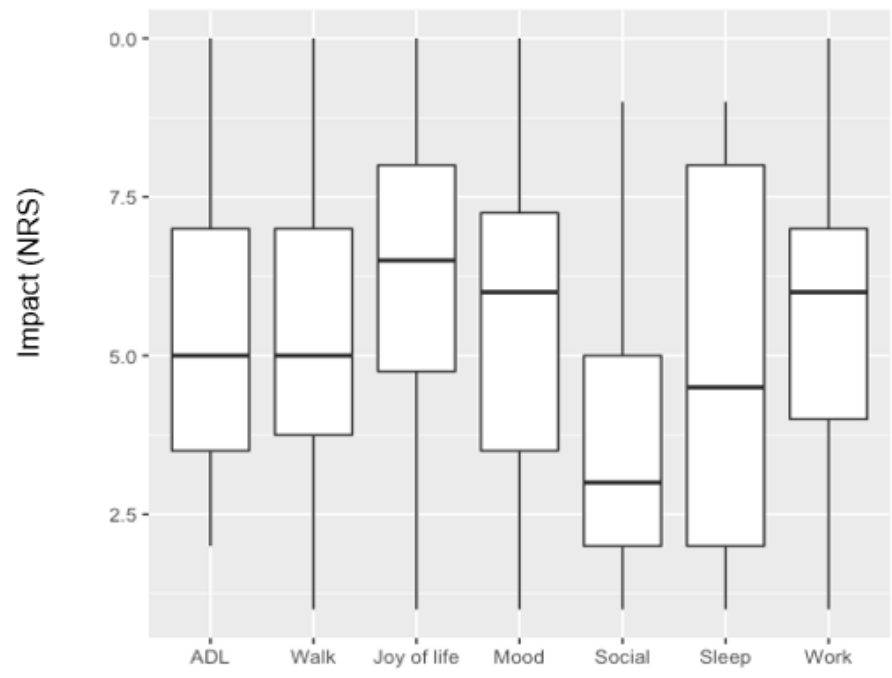

Self-perceived impact on activities of daily life 
Figure 2

BPI Mean intensity score (0-10) and Self-perceived impact on activities of daily life. BPI, Brief pain inventory; ADL, Activities of daily life; NRS, Numeric rating scale.
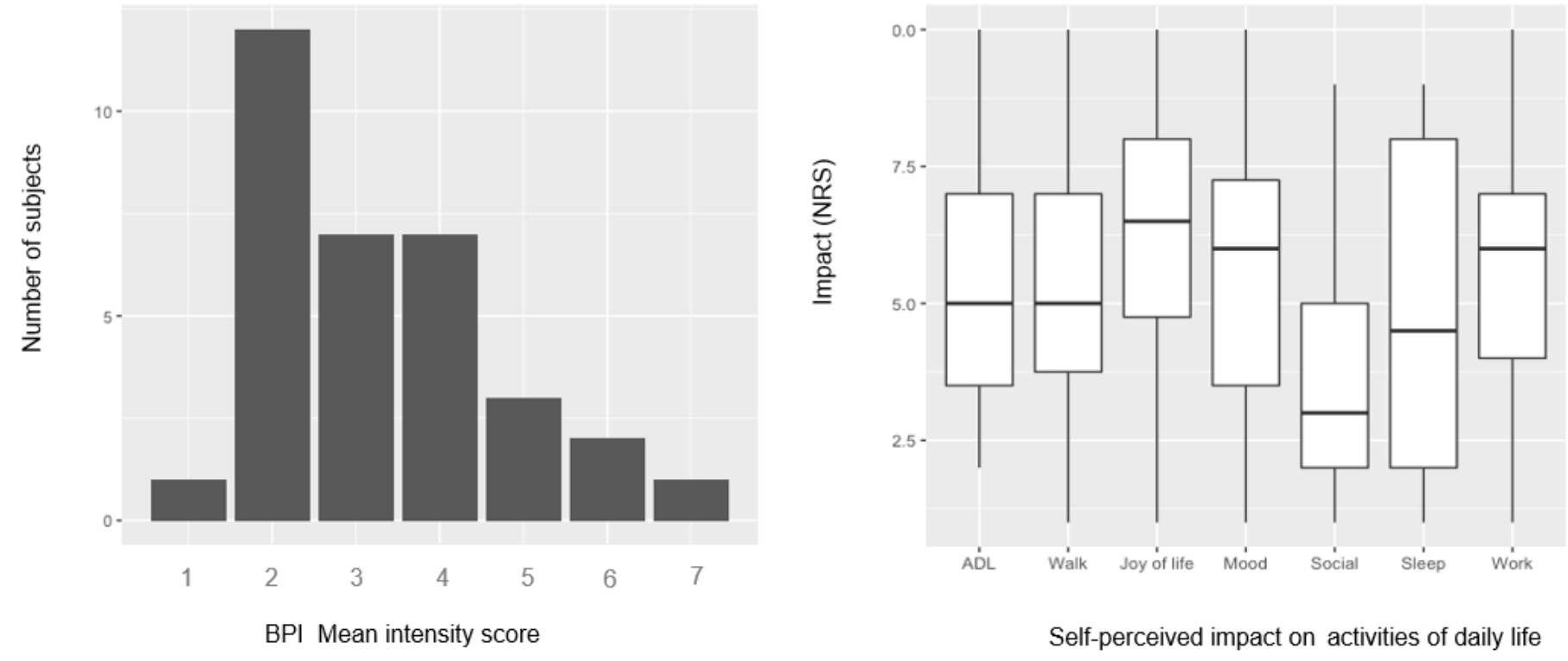

Figure 2

BPI Mean intensity score (0-10) and Self-perceived impact on activities of daily life. BPI, Brief pain inventory; ADL, Activities of daily life; NRS, Numeric rating scale. 


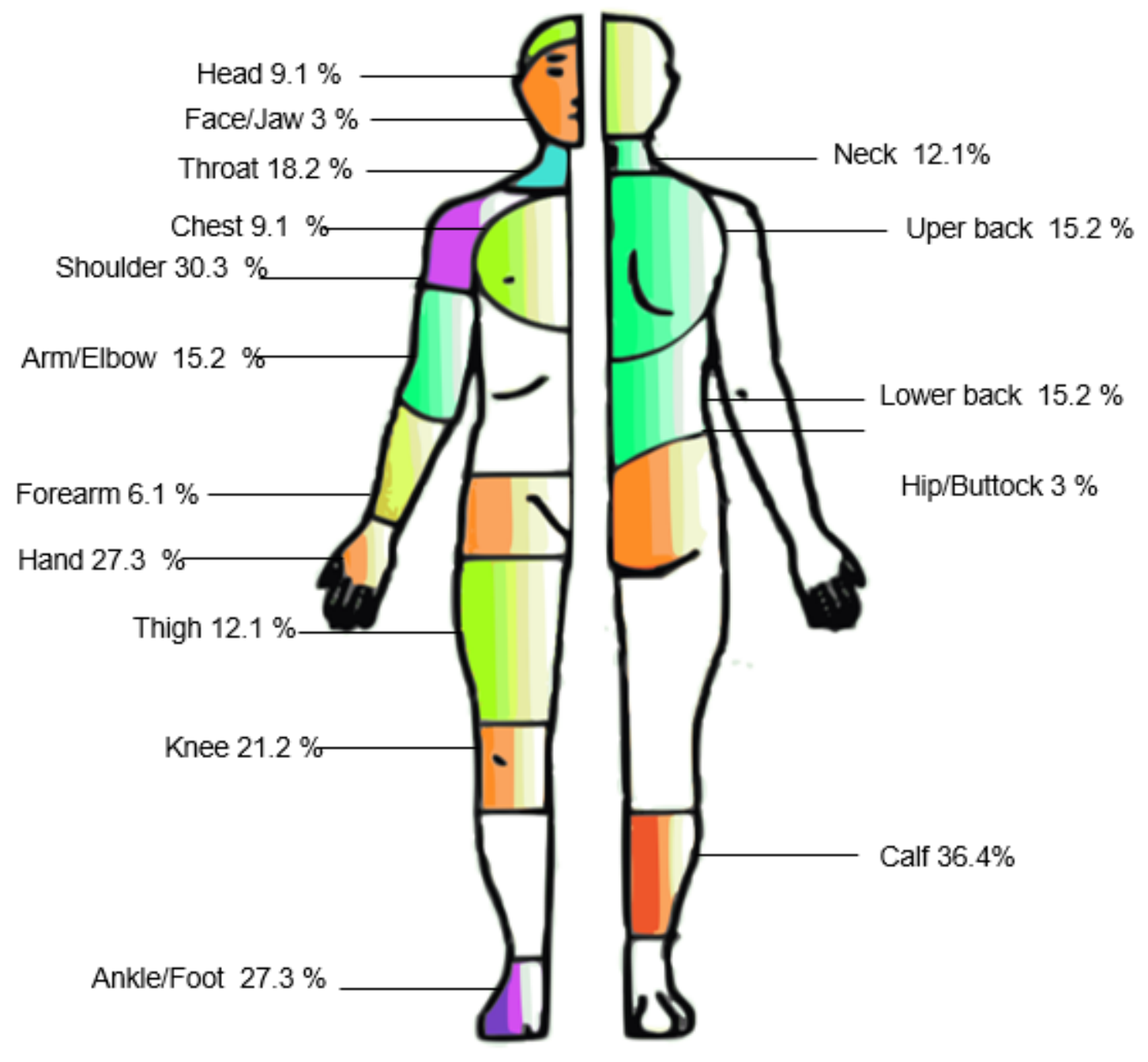

Figure 3

Body map of pain locations. 


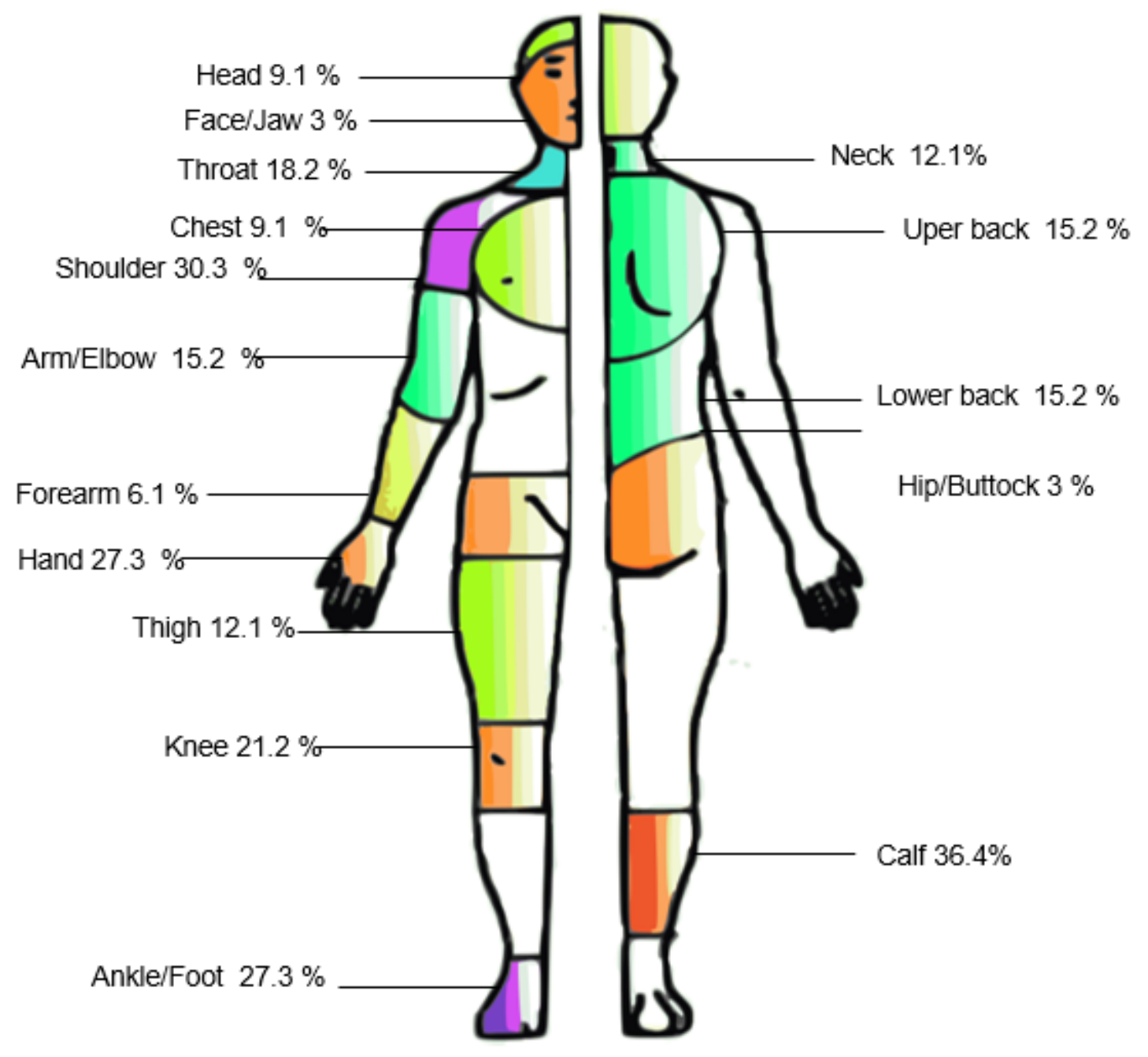

Figure 3

Body map of pain locations.
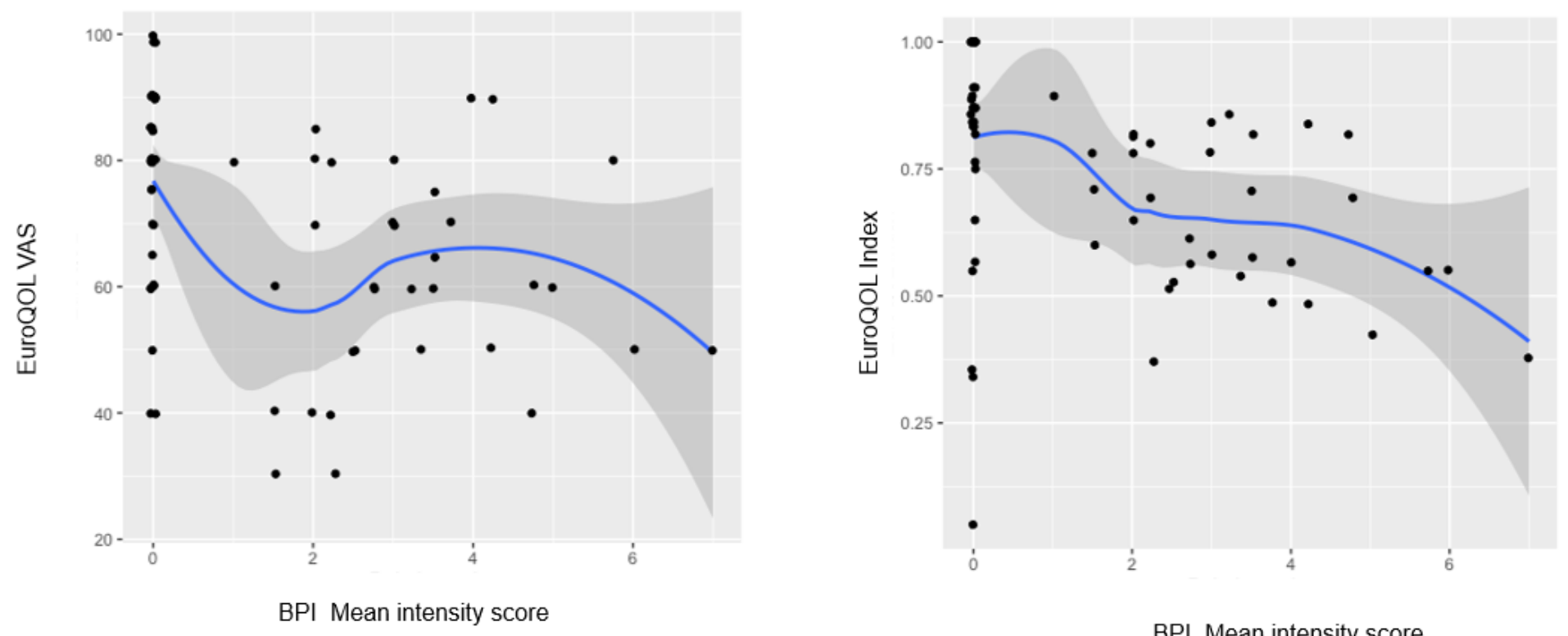

BPI Mean intensity score 


\section{Figure 4}

BPI Intensity correlation with EuroQoL VAS and EuroQoL Index. The grey shade area represents the 95\% confidence interval. BPI, Brief pain inventory ;VAS, Visual analogue scale ;EuroQOL, European Quality of Life scale.

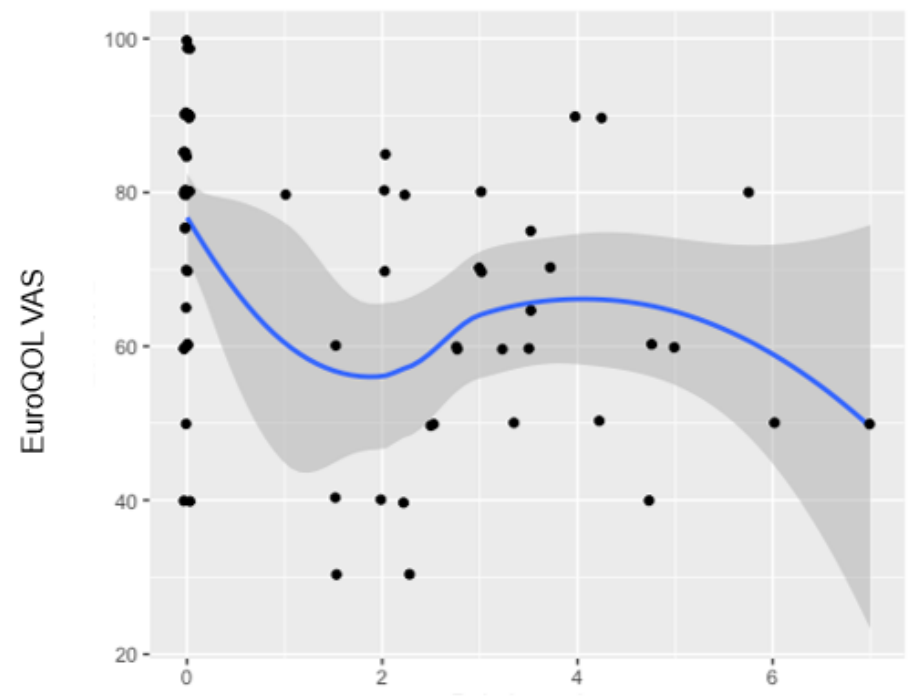

BPI Mean intensity score

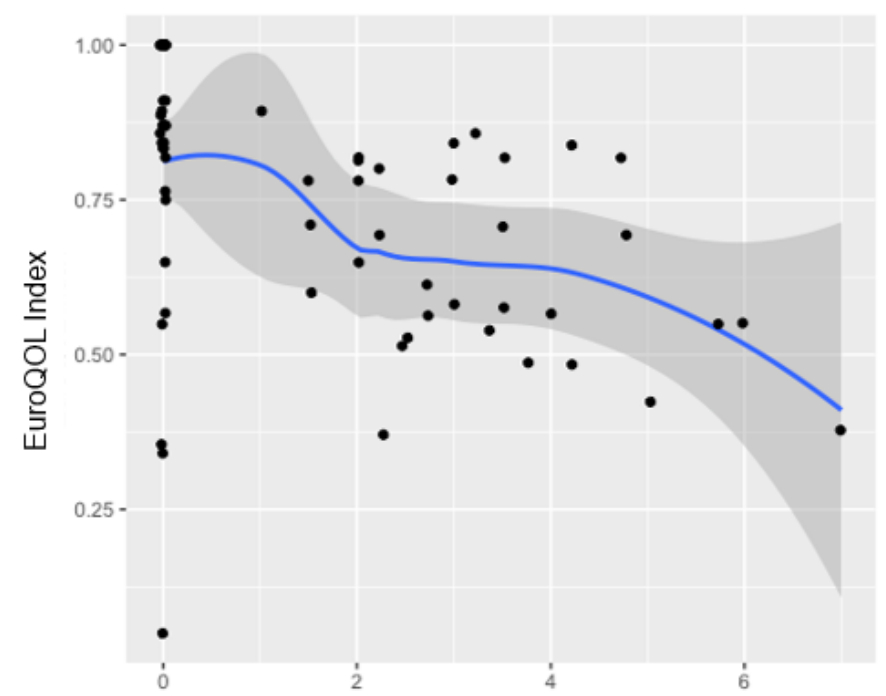

BPI Mean intensity score

\section{Figure 4}

BPI Intensity correlation with EuroQoL VAS and EuroQoL Index. The grey shade area represents the $95 \%$ confidence interval. BPI, Brief pain inventory ;VAS, Visual analogue scale ;EuroQOL, European Quality of Life scale.

\section{Supplementary Files}

This is a list of supplementary files associated with this preprint. Click to download.

- graphicabstract.jpg

- graphicabstract.jpg

- STROBEchecklistv4combinedPlosMedicine.docx

- STROBEchecklistv4combinedPlosMedicine.docx

- SUPPLEMENT.docx

- SUPPLEMENT.docx 